\title{
Which preoperative screening tool should be applied to older patients undergoing elective surgery to predict short-term postoperative outcomes? Lessons from systematic reviews, meta-analyses and guidelines
}

\author{
Rachel Aitken ${ }^{1} \cdot$ Nur-Shirin Harun ${ }^{2} \cdot$ Andrea Britta Maier $^{1,3}$ \\ Received: 18 May 2020 / Accepted: 20 June 2020 / Published online: 1 July 2020 \\ (C) The Author(s) 2020
}

\begin{abstract}
Background Older surgical patients have a higher risk of postoperative mortality and morbidity compared to younger patients. Timely identification of high-risk patients facilitates comprehensive preoperative evaluation, optimization, and resource allocation to help reduce this risk. This review aims to identify a preoperative screening tool for older patients undergoing elective surgery predictive of poor short-term postoperative outcomes.

Methods A scoping review was conducted. An Ovid MEDLINE search was used to identify systematic reviews or metaanalyses comprising older elective patients in at least two different surgical settings. International guidelines were reviewed for recommendations regarding preoperative tools in this population.

Results Over 50 screening tools were identified. The majority showed a positive association with short-term postoperative mortality and morbidity in older patients. The most commonly described tools were the American Society of Anesthesiologists Physical Status (ASA-PS), frailty tools and domain-specific tools administered as part of comprehensive geriatric assessment (CGA). Due to heterogeneity in outcome measures and statistical methodology the predictive capacity between tools could not be compared. International guidelines described a comprehensive preoperative approach incorporating domain-specific tools rather than recommending a screening tool.

Conclusion Multiple tools were associated with poor short-term postoperative outcomes in older elective surgical patients. No single superior tool could be identified. Frailty, cognitive and/or functional tools were most frequently utilized.
\end{abstract}

Keywords Geriatric assessment $\cdot$ Aged $\cdot$ Screening tool $\cdot$ Preoperative care $\cdot$ Surgery $\cdot$ Frailty

Rachel Aitken and Nur-Shirin Harun have contributed equally.

Electronic supplementary material The online version of this article (https://doi.org/10.1007/s11739-020-02415-y) contains supplementary material, which is available to authorized users.

Andrea Britta Maier

a.b.maier@vu.nl

1 Department of Medicine and Aged Care, The University of Melbourne, The Royal Melbourne Hospital, @ AgeMelbourne, Parkville, VIC, Australia

2 Department of Medicine, The Royal Melbourne Hospital, Melbourne, Australia

3 Department of Human Movement Sciences, Faculty of Behavioural and Movement Sciences, Vrije Universiteit Amsterdam, Amsterdam Movement Sciences, @ AgeAmsterdam, Amsterdam, The Netherlands

\section{Background}

Older people constitute the most rapidly growing group throughout the developed world [1]. This evolving demographic shift has led to an increased demand for surgery in older patients [2]. Older patients are more likely to suffer from multi-morbidity, frailty, cognitive and functional impairment [3]. As a result, they have poorer postoperative outcomes including higher mortality and complication rates, a prolonged length of stay and increased likelihood of discharge to supported accommodation compared to younger patients $[4,5]$. Equally important measures of recovery, such as health-related quality of life, are infrequently reported and poorly defined [6].

Efficient and effective screening of older patients who may be at increased risk of these poor postoperative 
outcomes is a current challenge facing clinicians and service providers. Identification of high-risk older patients aims to improve postoperative outcomes through targeted comprehensive geriatric assessment (CGA) and medical optimization, shared decision-making, engagement of the perioperative multidisciplinary team and allocation of critical care resources [7-9]. Conversely, not all older patients will benefit from these interventions.

There is lack of consensus on which screening tools should be applied to older patients in an elective surgical setting [10]. Although there is an abundance of tools in existence, many are narrowly targeted towards specific surgical subtypes or require specialist training to administer. Thus, a preoperative assessment tool that can be easily and broadly applied to older elective surgical patients with a high ability to predict poor postoperative outcomes is sought.

This scoping review aims to examine the ability of preoperative assessment tools to predict poor short-term postoperative outcomes in older patients undergoing elective surgery and to determine if a single best screening tool can be recommended in this cohort. We also aim to summarize recommendations for the use of these preoperative assessment tools in relevant international guidelines on the perioperative care of the older patient.

\section{Methods}

Given the broad research question with anticipated heterogenous results, a scoping review based on Arksey and O'Malley's framework was conducted [11].

\section{Search strategy}

We searched Ovid MEDLINE for systematic reviews and meta-analyses of preoperative tools applied to older patients undergoing elective surgery published between January 2000 and 8 February 2019. The literature search was conducted with assistance from a health sciences librarian. Keywords were combined with MeSH search terms 'surgical procedures, operative', 'elective surgical procedures', 'risk assessment or risk factors', 'outcome assessment (health care)', 'decision support techniques', 'postoperative complications', 'mortality', 'morbidity', 'length of stay' and 'treatment outcome'. The detailed search string is listed in electronic supplementary material. The inclusion of international guidelines was deemed necessary after the literature search of systematic reviews and meta-analyses lacked a clear consensus on which screening tools were best to use in the population of interest.

\section{Review procedure}

Two investigators (RA, NSH) screened the titles and abstracts and selected articles for full-text review. Full-text articles were then examined for eligibility. A third researcher $(\mathrm{ABM})$ resolved any differences that could not be decided by consensus. A manual search of the references of eligible articles was also performed. In addition, relevant international guidelines evaluating older patients undergoing elective surgery were screened for recommendations regarding evidence-based preoperative tools.

\section{Inclusion criteria}

Eligible articles consisted of systematic reviews or metaanalyses in which the majority of study participants were older patients undergoing elective surgery. Older patients were defined as a population mean or median age of 60 years or older. If the age range was not stated in the review article, original articles were examined. Screening tools needed to be tested in at least two different elective surgical populations. This ensured the tools were not limited to a specific surgical group and were therefore more broadly applicable. Tools needed to be able to be completed preoperatively. Outcomes of interest were short-term mortality (inpatient mortality, 30-day or 90-day mortality), length of stay and measures of short-term postoperative morbidity such as postoperative complications, postoperative delirium, quality of life and discharge to a care facility.

\section{Results}

The literature search yielded 3814 articles. Screening of titles and abstracts resulted in 69 articles selected for fulltext review. Following the exclusion of articles based on study type, patient population, tools and outcomes, 15 articles were selected for inclusion [12-26] as detailed in Fig. 1.

More than 50 different preoperative tools were identified. The American Society of Anesthesiologists Physical Status (ASA-PS) tool, several frailty tools and domain-specific tools included as part of CGA were most frequently reported. Characteristics of the included studies are listed in Table 1. Tools and association with postoperative mortality and morbidity are detailed in Table 2.

\section{American Society of Anesthesiologists Physical Status (ASA-PS)}

The ASA tool is a simple ranking of physical health status from 1 to 5 (independent-moribund), which can be 
Fig. 1 Flowchart of selection of articles for inclusion in review

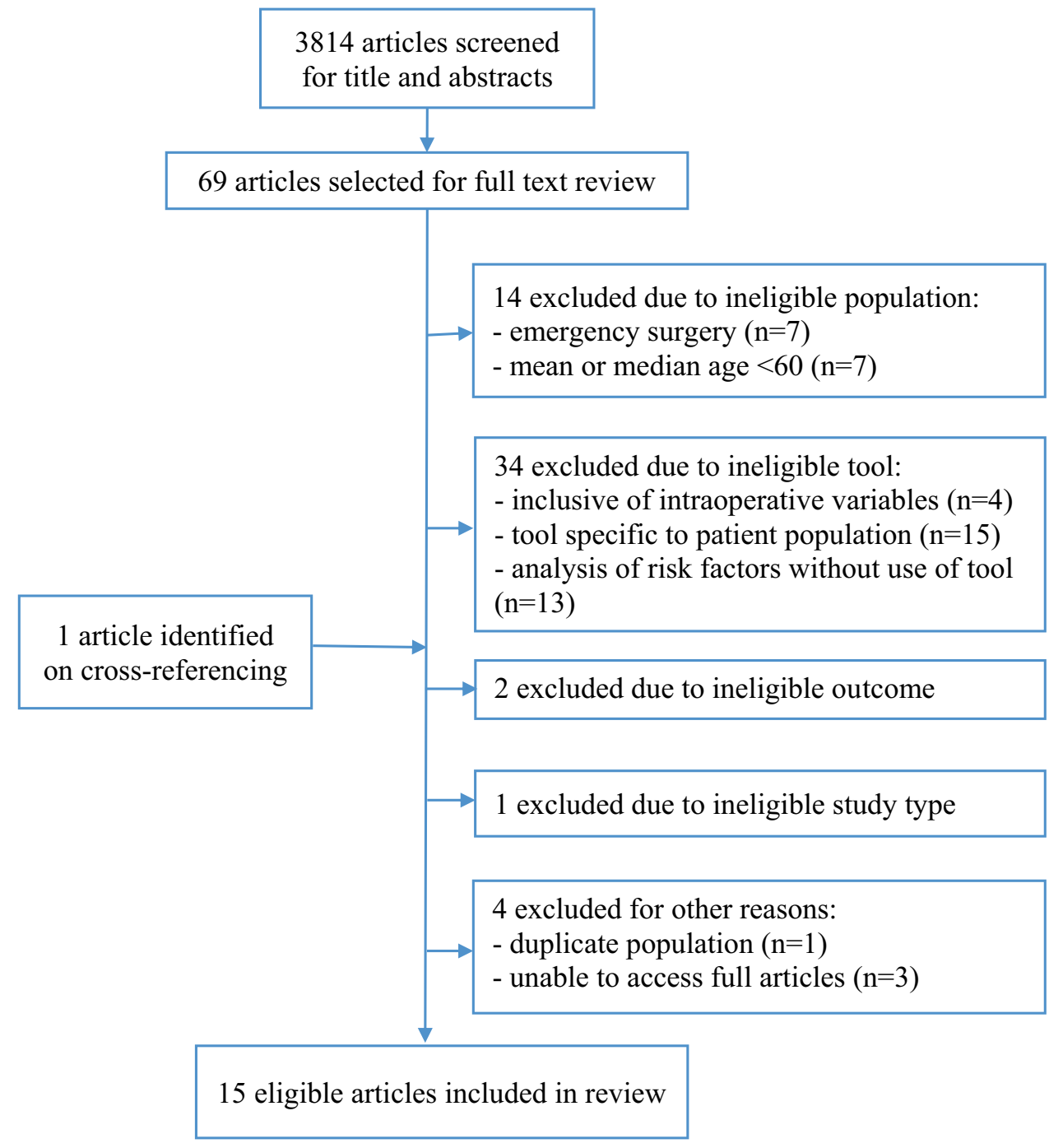

completed quickly by a wide range of clinicians [27]. It is broadly applied to all ages and to both emergency and elective populations. An association of high ASA grade with postoperative delirium $[18,22,26]$ and postoperative mortality as well as complications [24] was reported in older patients undergoing a range of elective surgery. Conversely, a poor AUROC of 0.64 for the ability of the ASA to predict postoperative mortality following oesophagectomy was described [25].

\section{Frailty}

Of the multitude of frailty tools applied to older surgical patients across nine reviews [12-17, 19, 21, 23], including cardiothoracic surgical patients $[12,13,17]$, the modified frailty index $(\mathrm{mFI})$ and Fried criteria were the most frequently reported, followed by the Comprehensive Assessment of Frailty (CAF), Groningen Frailty Index (GFI) and Balducci frailty criteria. A strong association between the
mFI and postoperative mortality and Clavien-Dindo grade 4 or 5 postoperative complications were reported in frail patients undergoing mixed major surgery [13]. In a metaanalysis and systematic review, frail patients (defined as any mFI score $>0$ ) had a higher 30-day mortality (RR 4.19, CI 2.96-5.92), higher major postoperative complications (RR 2.03, CI 1.26-3.29) and an higher likelihood of discharge to skilled care accommodation (RR 2.15, CI 1.92-2.4) compared to non-frail patients (mFI score of 0) [19]. Similarly, frail patients meeting at least 3 of 5 phenotypic Fried scale criteria were more likely to die (30-day mortality OR 2.67, $p=0.029$ ) [17], develop major postoperative complications [13] and have a longer length of stay (median LOS 9 vs 6 days, $p=0.004$ ) [19]. Sandini et al. reported a strong association between frailty and 90-day postoperative mortality [OR 5.77, (CI 4.41-7.55)] and major morbidity [OR 2.56 (CI 2.08-3.16)] in older patients undergoing mixed major surgery, although did not specify a suggested frailty tool [21]. Overall, the majority of frailty tools summarized in 
40

Internal and Emergency Medicine (2021) 16:37-48

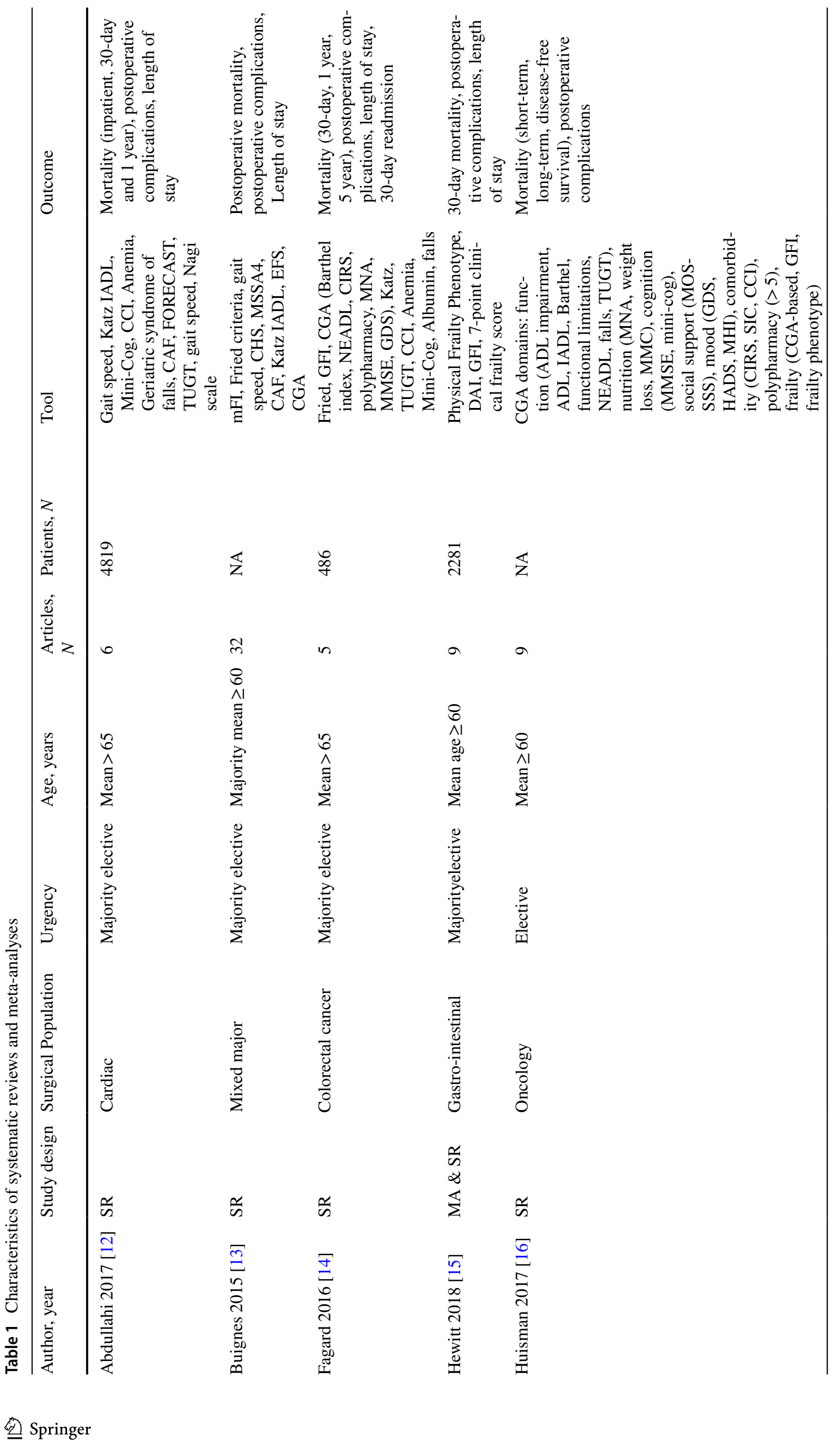




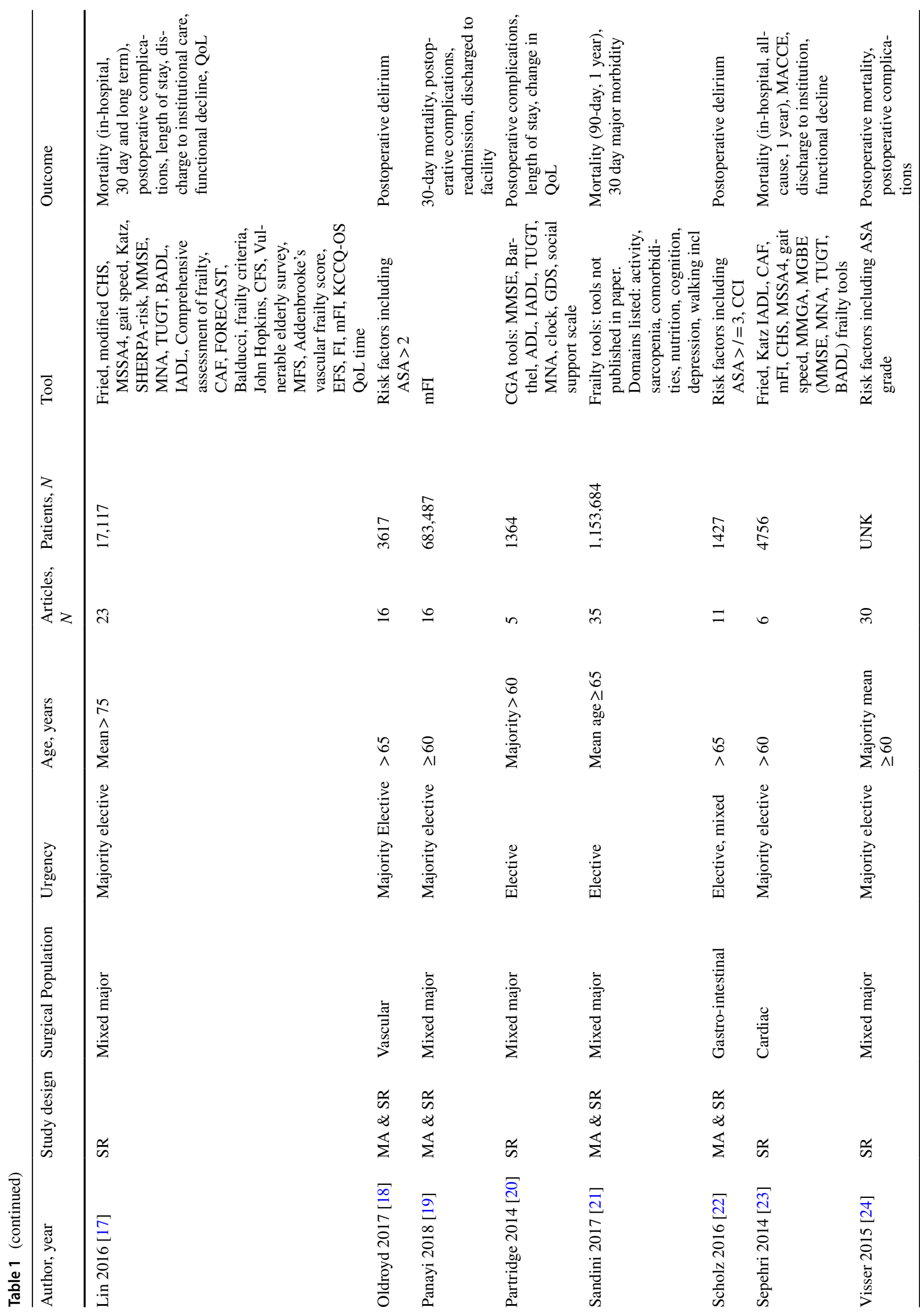




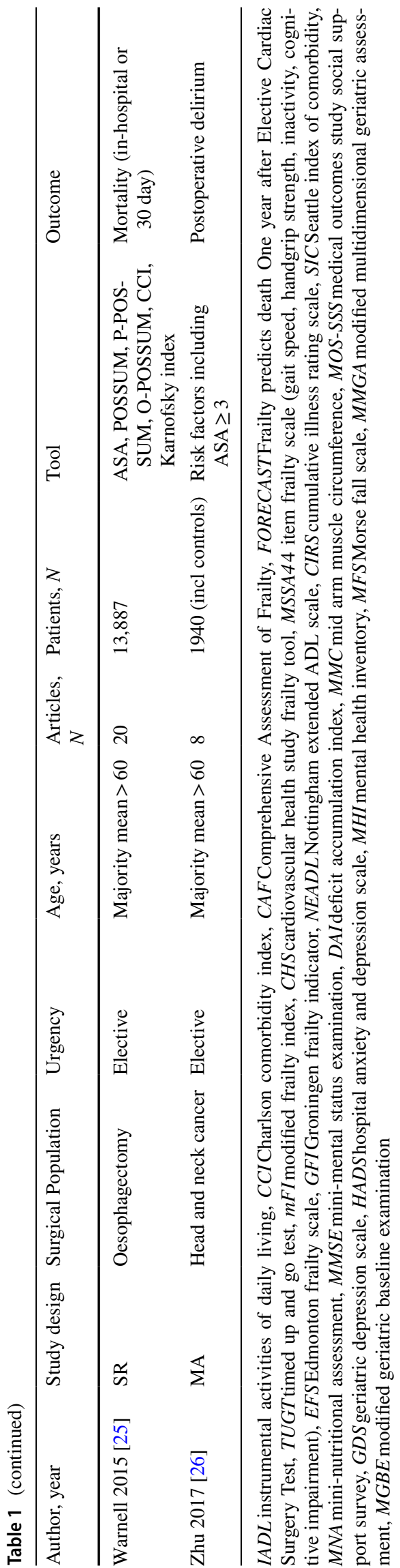

this review reported a positive association with morbidity and mortality in older patients undergoing elective surgery.

\section{Function}

Tools to assess function were applied as part of frailty screening and CGA. Gait speed and the timed up and go test (TUGT) were described as bedside preoperative functional tests. Slow gait speed defined as $5 \mathrm{~m} \geq 6 \mathrm{~s}$ was associated with higher postoperative mortality [13], and composite endpoint of postoperative mortality or major morbidity (OR ranging 2.63 (CI 1.17-5.9) to 3.17 (CI 1.7-2.59) [12, 23]. TUGT over $20 \mathrm{~s}$ was associated with postoperative complications [OR ranging from 3.1 (CI 1.1-8.6) to 4.1 (CI 1.6-10.5)] [16] in older patients undergoing oncologic surgery. Clinician or patient-measured functional scales including the Katz, Barthel, Instrumental Activities of Daily Living (IADL) and Nottingham extended ADL scale (NEADL) tools demonstrated an association between functional impairment and increased postoperative mortality [12, $16]$ and 30-day postoperative complication rate [16].

\section{Comprehensive geriatric assessment (CGA)}

Several objective tools as part of CGA were evaluated and categorized into functional, nutritional, cognitive, mood, comorbidity, polypharmacy and frailty domains [16]. Patients at risk of malnourishment using the Mini Nutritional Assessment (MNA) had a higher risk of short-term postoperative mortality (HR 2.39, CI 1.24-4.61) [16]. Those with a mini-mental status examination (MMSE) score $<24$ points had an increased risk of mortality (HR 1.13, CI 1.04-1.22) and postoperative complications (OR 4.55, CI 1.15-18.05) within 6 months following surgery [16]. Older surgical patients with a geriatric depression scale $\geq 5$ points were also less likely to survive 6 months (HR 3.62, CI 1.77-7.4) and were more likely to experience postoperative complications [OR range 3.68 (CI 0.96-14.08) to 4.58 (CI 125-16.84)] [16]. Partridge et al. reviewed overall CGA application encompassing the use of objective tools and demonstrated lower postoperative complications and length of stay (4.9 vs 8.9 days, $p<0.001$ ) [20].

\section{Current guidelines on perioperative management of older patients}

Recommendations summarized in international guidelines on the perioperative care of older patients are given in Table 3 [28-33]. Most are based on expert consensus opinion. Where validated screening tools have been used to assess individual domains, these are highlighted.

The American College of Surgeons National Surgical Quality Improvement Program (NSQIP) 2012 guideline 
Table 2 Predictive capacity of preoperative assessment tools

\begin{tabular}{|c|c|c|}
\hline Tool & Mortality & Morbidity and length of stay \\
\hline ASA & $\begin{array}{l}\text { AUROC } 0.64 \text { [25] } \\
\text { OR 1.54-11.6 [24] }\end{array}$ & $\begin{array}{l}\text { Postop complications: } \\
\text { OR } 1.77-7.1[24] \\
\text { ASA }>2 \text { : OR 3.44 (2.02-5.87) [18] } \\
\text { ASA-3: Clavien-Dindo } 4 \text { OR } 6.8[13] \\
\text { ASA } \geq 3 \text { : pooled OR } 2.71(1.64-4.48)[22] \\
\text { Delirium: } \\
\text { ASA } \geq 3: \text { OR } 5.65 \text { (1.57-20.36) [26] } \\
\text { Cardiac arrest: } \\
\text { ASA-3: OR 1.2, ASA-4: OR 3.5, ASA-5: OR } 7.5 \text { [13] } \\
\text { Perioperative MI: } \\
\text { ASA-3: OR 3, ASA-4: } 6.9, \text { ASA-5: } 14.9 \text { [13] }\end{array}$ \\
\hline CAF & $\leq 1130 \mathrm{~d}$ mortality OR $1.1(1.06-1.2)[12]$ & \\
\hline $\mathrm{CCI}$ & $\begin{array}{l}\text { AUROC } 0.57 \text { [25] } \\
\text { All-cause mortality HR } 1.03(0.9-1.17)[16]\end{array}$ & $\begin{array}{l}\text { Postop complications: } \\
\text { OR } 0.93(-1.68-3.54)[22]\end{array}$ \\
\hline CGA assessment of frailty & $\begin{array}{l}2 \text { frailty markers: } \\
6 \text { mo mortality HR } 3.86(0.41-36.02)-8.88(1.09-72.29) \\
\quad[16] \\
\geq 3 \text { markers: } \\
6 \text { mo mortality HR } 4.51(0.49-41.25)-8.5(1.1-65.87) \\
\quad[16]\end{array}$ & $\begin{array}{l}\text { Postop complications: } \\
\text { OR } 3.13(1.65-5.92)-6[13,16] \\
\text { RR } 1.59(1.25-2.01)-1.75(1.28-2.41)[16] \\
\text { Length of stay } \\
\text { LOS }>2 \text { days OR } 4.2[13]\end{array}$ \\
\hline Fried & 30d mortality OR $2.67(p=0.029)[17]$ & $\begin{array}{l}\text { Postop complications: } \\
\text { OR } 2.54(1.12-5.77)[13] \\
\text { Major Cx OR } 3.13(1.65-5.92)-4.1[13] \\
\geq \text { Clavien } 2 \text { Cx OR } 4.08(p=0.006)[17] \\
\text { Mortality or procedural Cx OR } 2.2(p=0.04)[17] \\
\text { QoL } \\
\text { Mortality or poor QoL at } 6 \text { mo OR } 2.21(p=0.03) \text { [17] } \\
\text { Length of stay } \\
\text { LOS intermediately frail OR } 1.49(1.24-1.8)[13]\end{array}$ \\
\hline GFI & GFI $\geq 5$ 30d mortality ES $0.08(0.02-0.21)[15]$ & $\begin{array}{l}\text { Postop complications: } \\
\text { GFI } \geq 5 \text { Postop Cx ES } 0.15(0.06-0.31)[15] \\
\text { GFI } \geq 3 \geq \text { Clavien } 3 a \text { OR } 3.62[13] \\
\text { Length of stay } \\
\text { GFI } \geq 5 \text { ES } 7.17(6.02-8.54)[15] \\
\text { GFI } \geq 3 \text { ES } 15.8(12.79-19.51)[15]\end{array}$ \\
\hline Katz IADL & $\begin{array}{l}\text { Dependence in } \geq 1 \text { ADL inpatient mortality OR } 1.8 \\
(1.1-3)[23]\end{array}$ & \\
\hline $\mathrm{mFI}$ & $\begin{array}{l}\text { OR 11-11.7 [13] } \\
\text { RR 4.19 (2.96-5.92) [19] }\end{array}$ & $\begin{array}{l}\text { Postop complications: } \\
\text { OR 11[13] } \\
\text { Clavien } 4 \text { and } 5 \text { postop Cx OR } 14.4[13] \\
\text { mFI }>0.27 \text { : Clavien 4 Cx OR } 4.8[13] \\
\text { mFI > 0.12: postop Cx OR } 2.71[13] \\
\text { mFI }>0 \text { : postop Cx pooled RR } 1.48(1.35-1.61) \text {, major } \\
\quad \text { postop Cx pooled RR } 1.48(1.35-1.61)[19] \\
\text { Discharge to care facility: } \\
\text { RR 2.15 (1.92-2.4) [19] }\end{array}$ \\
\hline Slow gait speed $5 \mathrm{~m} \geq 6 \mathrm{~s}$ & OR $2.63[13]$ & $\begin{array}{l}\text { Mortality or major morbidity OR } 2.63(1.17-5.9)-3.17 \\
(1.7-2.59)[12]\end{array}$ \\
\hline
\end{tabular}

[29] is one of the earliest publications released in this field. It is relatively prescriptive and recommends specific preoperative testing, such as full blood examination and baseline ECG. Validated domain-specific assessment tools are recommended according to expert consensus. The NSQIP 2016 guideline [28] includes sections relating to the immediate perioperative period. It does not discuss screening tools, however, refer to the NSQIP 2012 guideline where screening tools are discussed in further detail, for example, in the medication management domain [28, 29].

The guidelines of the Association of Anaesthetists of Great Britain and Ireland [30] similarly refer to NSQIP 2012 for assessment of domains including cognition and medication management. These guidelines also recommend preoperative risk score calculation tailored to specific surgical situations, for example, use of the Nottingham Hip Fracture 


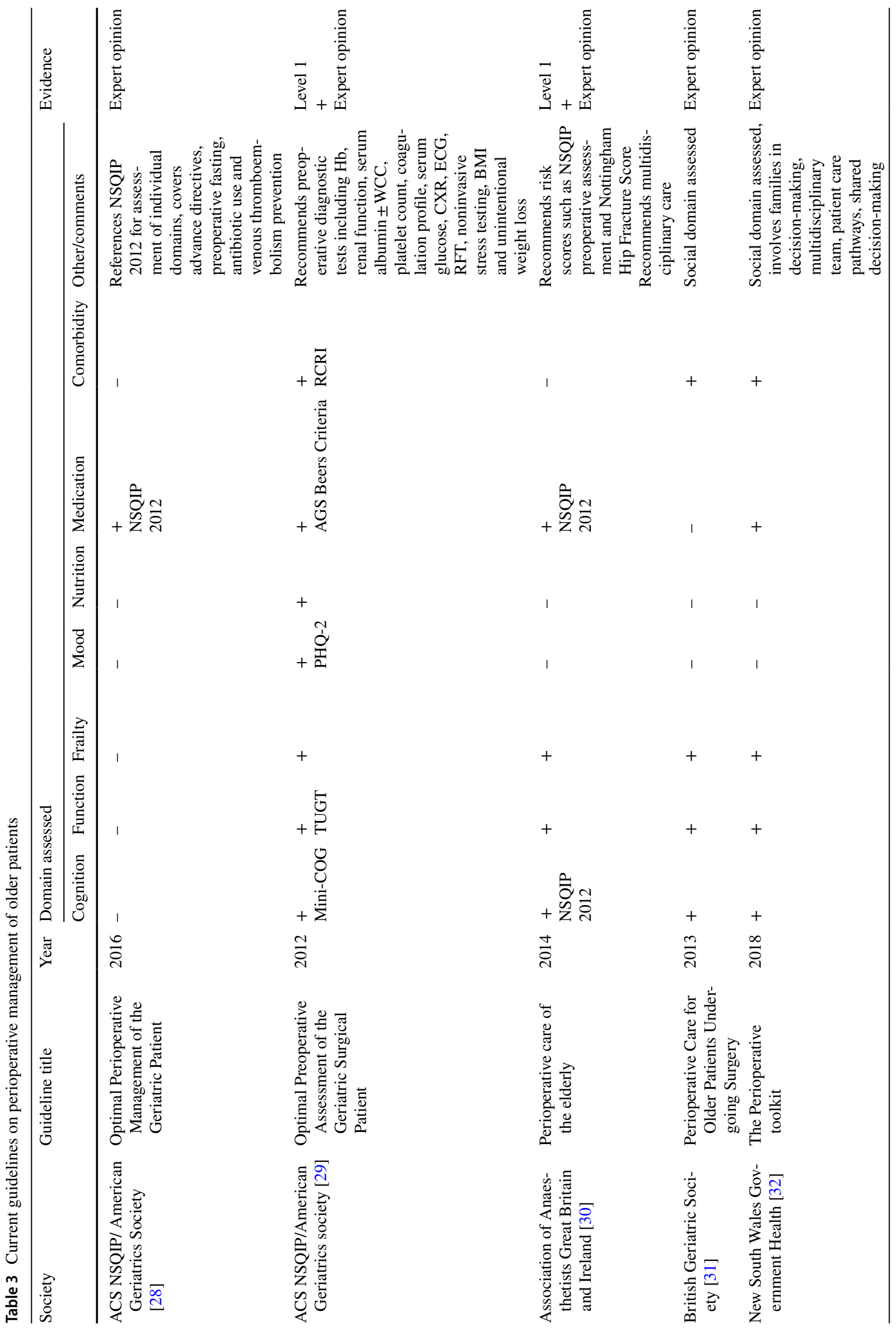


Score in the prediction of 30-day mortality after hip fracture surgery [30]. The British Geriatric Society guideline [31] and an Australian guideline, the New South Wales Government Health Perioperative toolkit [32], recommend assessing several domains to risk stratify patients, but do not specify which tools to use. Both these guideline emphasize the importance of assessing social domains which are not included in NSQIP guidelines [31, 32]. The Society for Perioperative Assessment and Quality Improvement (SPAQI) [33] covers several domains including cognition, functional status, frailty, mood disorder and medical comorbidity. Specific screening tools are suggested for some of the domains, such as mini-COG to assess cognition. The more recently published guidelines, including SPAQI and the New South Wales Government Health Perioperative Toolkit, tend to state broader expert consensus recommendations such as multidisciplinary care and shared decision-making [32, 33].

Overall, there is heterogeneity in the approach taken by each guideline committee towards the perioperative management of older patients. Assessment domains and tools differ between guidelines. Almost all guidelines recommend an assessment of cognition, functional status and frailty, although many do not specify which tool to use.

\section{Discussion}

This scoping review of systematic reviews and meta-analyses demonstrates the broad range of tools that are applied preoperatively to older patients undergoing elective surgery. The most commonly described tools include the ASA, frailty tools and tools utilized during CGA. The majority of tools show a positive association with short-term postoperative mortality and morbidity as measures of postoperative recovery in various older surgical patient populations, including cardiothoracic patients. Due to the differences in utilized cut-off points and outcome parameters, tools are unable to be compared in order to support one tool over another. Perioperative guidelines offer recommendations for pre-assessment approach in older surgical patients but lack consensus regarding the selection of preoperative tools. As a result, there is no evidence to support a distinct tool which should be applied universally to older surgical patients.

The ASA is simple to apply and routinely used by anaesthetists to broadly stratify patients in all perioperative settings. Whilst there is a consistent association between a higher ASA score and poor postoperative outcomes [34], it remains a subjective score with high inter-observer variability [35].

The inherent value of identifying frailty, defined as an age-related cumulative decline in multiple physiological systems [36], has been increasingly recognized as a measure of high-risk in older surgical patients $[9,37,38]$. However, 
standardized assessment is often lacking due to the absence of a universal or 'gold standard' frailty tool as demonstrated in this review.

CGA is a time-consuming patient-specific evaluation which might not be appropriate to administer to all older patients preoperatively [39]. Whilst there is supportive evidence for CGA in both emergency [40] and elective [41] older surgical patients, it requires specialist training to administer the domain-specific tools [20,21]. Adaptations of the CGA into screening tools such as the G-8 questionnaire [42] and CGA-GOLD [43] require further research in broad surgical populations and were not published in a meta-analysis or systematic review format for inclusion. Additional commonly utilized screening tools did not meet the inclusion criteria for this review. For example, the P-POSSUM uses intraoperative variables [44] and the Revised Cardiac Risk Index was only included in one systematic review within our literature search [45].

International guidelines are fairly consistent in terms of recommending a complete preoperative medical assessment based on geriatric domains included in a CGA. Most recommendations are based on expert opinion. Although cognition, functional status and frailty are consistently prioritized, with corresponding tools given as an example in each guideline, there is no consensus regarding which tool to use. This suggests that completing any chosen assessment may be more important than which tools are specifically used. The ease of use of the guidelines and ability to apply the recommendations quickly and effectively in an outpatient setting, such as a preadmission clinic, has not been validated. Furthermore, a comprehensive approach might not necessary for all older patients.

The 2018 Royal College of Surgeons High-Risk General Surgical Guideline recommends all patients undergo risk assessment prior to surgery and classifies patients with a predicted postoperative mortality risk of $\geq 5 \%$ as high risk [9]. This can be estimated using a preoperative risk assessment tools and frailty assessment. Resources can consequently be targeted towards high-risk patients including planning postoperative critical care beds, senior anaesthetic and surgical intraoperative presence and engagement of the multidisciplinary perioperative team. Whilst no screening tool has been identified as the single best option in the older general surgical patient, it appears that making a screening assessment using any validated tool to guide the application of comprehensive geriatric assessment is warranted. Given the shared recommendation of guidelines to assess cognition, functional status and frailty, it is reasonable for clinicians to choose a tool within one or all of these domains.

There were limitations met throughout this scoping review which contributed to the inability to define a single appropriate screening tool. The high number of tools reported and marked heterogeneity in outcomes measured significantly limited the ability to compare tools in this review. Whilst narrowing the search to a more specific population may have been more achievable, we aimed to find a broadly applicable tool to reflect clinical need and simplify perioperative pathways. There were multiple selection biases including skewed subsurgical groups, the underrepresentation of oldest old patients and geography.

Geriatrician-led multidisciplinary perioperative care targeting older patients undergoing surgery is growing in clinical practice. The establishment of the 'Perioperative Care of Older Patients Undergoing Surgery' (POPS) service in the UK is an example of a successful collaborative perioperative model for older patients, which has led to improved mortality and morbidity in older surgical patients $[41,46]$. In this model, preoperative screening is not limited to a specific tool but encourages identification of geriatric syndromes and clinical judgement [47]. Despite strong evidence and UK national endorsement of the POPS model of care, clinical uptake is not yet widely disseminated with an acknowledged 'implementation gap'. A logic implementation model of the POPS service has successfully led to translation of core components to a smaller setting [48].

\section{Conclusion}

The use of screening tools to predict postoperative outcomes in older patients prior to elective surgery is important in identifying high-risk patients and developing safe, efficient and effective clinical pathways for the perioperative team. A number of screening tools have been identified as associated with poor postoperative outcomes and the selection of a frailty, functional and/or cognitive tool is proposed. International consensus guidelines recommend a complete and thorough medical and geriatric assessment of the older patient prior to surgery; screening tools can help guide which patients will benefit from this comprehensive approach.

\section{Author contributions and authorship}

All authors meet the International Committee of Medical Journal Editors (ICMJE) criteria for authorship. RA: $40 \%$ contribution (study design, literature search, results Tables 1, 2, Fig. 1, manuscript drafting and editing, reference collation). NSH: $40 \%$ contribution (study design, literature search, review of guidelines, results Table 3, manuscript drafting and editing). ABM: 20\% contribution (study design, manuscript editing, research supervisor).

Acknowledgements The authors would like to acknowledge Mr Patrick Condron, Senior Liaison Librarian, Melbourne Medical School, 
Melbourne Dental School, Melbourne School of Psychological Sciences, The University of Melbourne.

Funding This research is based on an unrestricted grant provided by the University of Melbourne received by Prof. Andrea B. Maier.

\section{Compliance with ethical standards}

Conflict of interests There are no conflicts of interest to disclose.

Statement of human and animal rights This review was conducted following accepted princlples of ethical and professional conduct. The research did not involve human participants or animals.

Informed consent None.

Open Access This article is licensed under a Creative Commons Attribution 4.0 International License, which permits use, sharing, adaptation, distribution and reproduction in any medium or format, as long as you give appropriate credit to the original author(s) and the source, provide a link to the Creative Commons licence, and indicate if changes were made. The images or other third party material in this article are included in the article's Creative Commons licence, unless indicated otherwise in a credit line to the material. If material is not included in the article's Creative Commons licence and your intended use is not permitted by statutory regulation or exceeds the permitted use, you will need to obtain permission directly from the copyright holder. To view a copy of this licence, visit http://creativecommons.org/licenses/by/4.0/.

\section{References}

1. United Nations, Department of Economic and Social Affairs, Population Division (2015) World Population Ageing 2015 (ST/ ESA/SER.A/390)

2. Etzioni DA, Liu JH, Maggard MA et al (2003) The aging population and its impact on the surgery workforce. Ann Surg 238:170-177

3. Gordon AL, Evans BJ, Dhesi J (2017) The physician's role in perioperative management of older patients undergoing surgery. Clin Med (London) 17(4):357-359

4. Polanczyk CA, Marcantonio E, Goldman L et al (2001) Impact of age on perioperative complications and length of stay in patients undergoing non cardiac surgery. Ann Intern Med 134:637-643

5. Hamel MB, Henderson WG, Khuri SF et al (2005) Surgical outcomes for patients aged 80 and older: morbidity and mortality from major noncardiac surgery. J Am Geriatric Soc 53(5):424-429

6. Bowyer AJ, Royse CF (2016) Postoperative recovery and outcomes-what are we measuring and for whom? Anaesthesia 71(S1):72-77

7. Shipway DJH, Harari D, Dhesi J (2014) Peri-operative management of older people undergoing surgery. Rev Clin Gerontol 24(1):78-92

8. Dhesi J (2012) Improving outcomes in older patients undergoing elective surgery. Aging Health (London) 8(4):329-332

9. The Royal College of Surgeons of England and Department of Health (2018) The high-risk general surgical patient: raising the standard. Updated recommendations on the perioperative care of the high-risk general surgical patient. https://www.rcseng.ac.uk/-/ media/files/rcs/news-and-events/media-centre/2018-press-relea ses-documents/rcs-report-the-highrisk-general-surgical-patie nt--raising-the-standard--december-2018.pdf. Accessed 25 June 2020

10. Eamer G, Al-Amoodi MJH, Holroyd-Leduc J et al (2018) Review of risk assessment tools to predict morbidity and mortality in elderly surgical patients. Am J Surg 216:585-594

11. Arksey H, O'Malley L (2005) Scoping studies: towards a methodological framework. Int J Soc Res Methodol 8(1):19-32

12. Abdullahi YS, Athanasopoulos LV, Casula RP et al (2017) Systematic review on the predictive ability of frailty assessment measures in cardiac surgery. Interact Cardiovasc Thorac Surg 24:619-624

13. Buignes C, Juarros-Folgado P, Fernandez-Garrido J et al (2015) Frailty syndrome and pre-operative risk evaluation: a systematic review. Arch Gerontol Geriatr 61:309-321

14. Fagard K, Leonard S, Deschodt M et al (2016) The impact of frailty on postoperative outcomes in individuals aged 65 and over undergoing elective surgery for colorectal cancer: a systematic review. J Geriatr Oncol 7:479-491

15. Hewitt J, Long S, Carter B et al (2018) The prevalence of frailty and its association with clinical outcomes in general surgery: a systematic review and meta-analysis. Age Ageing 47:793-800

16. Huisman MG, Kok M, de Bock GH et al (2017) Delivering tailored surgery to older cancer patients: preoperative geriatric assessment domains and screening tools-a systematic review of systematic reviews. EJSO 43:1-14

17. Lin H, Watts JN, Peel NM et al (2016) Frailty and post-operative outcomes in older surgical patients: a systematic review. BMC Geriatr 16:157

18. Oldroyd C, Scholz AFM, Hinchliffe RJ et al (2017) A systematic review and meta-analysis of factors for delirium in vascular surgical patients. J Vasc Surg 66:1269-1279

19. Panayi AC, Orkaby AR, Sakthivel D, et al (2018) Impact of frailty on outcomes in surgical patients: a systematic review and meta-analysis. Am J Surg. ISSN 0002-9610. https://doi. org/10.1016/j.amjsurg.2018.11.020.

20. Partridge JSL, Harari D, Martin FC et al (2014) The impact of pre-operative comprehensive geriatric assessment on postoperative outcomes in older patients undergoing scheduled surgery: a systematic review. Anaesthesia 69(Suppl. 1):8-16

21. Sandini M, Pinotti E, Persico I et al (2017) Systematic review and meta-analysis of frailty as a predictor of morbidity and mortality after major abdominal surgery. BJS Open 1:128-137

22. Scholz AFM, Oldroyd C, McCarthy K et al (2016) Systematic review and meta-analysis of risk factors for postoperative delirium among older patients undergoing gastrointestinal surgery. BJS 103:e21-28

23. Sepehri A, Beggs T, Hassan A et al (2014) The impact of frailty on outcomes after cardiac surgery: a systematic review. J Thorac Cardiovasc Surg 148:3110-3117

24. Visser A, Geboers B, Gouma DJ et al (2015) Predictors of surgical complications: a systematic review. Surgery 158:58-65

25. Warnell I, Chincholkar M, Eccles M (2015) Predicting perioperative mortality after oesophagectomy: a systematic review of performance and methods of multivariate models. Br J Anaesth 114(1):32-43

26. Zhu Y, Wang G, Liu S et al (2017) Risk factors for postoperative delirium in patients undergoing major head and neck cancer surgery: a meta-analysis. Jpn J Clin Oncol 47(6):505-511

27. American Society of Anesthesiologists. ASA Physical Status Classification System. Last amended Oct 15 2014. https://www. asahq.org/standards-and-guidelines/asa-physical-status-class ification-system. Accessed 12 Jan 2019

28. Mohanty S, Rosenthal RA, Russell MM et al (2016) Optimal perioperative management of the geriatric patient: a best practices guideline from the American College of Surgeons 
NSQIP and the American Geriatrics Society. J Am Coll Surg 222(5):930-947

29. Chow WB, Rosenthal RA, Merkow RP et al (2012) Optimal preoperative assessment of the geriatric surgical patient: a best practices guideline from the American College of Surgeons National Surgical Quality Improvement Program and the American Geriatrics Society. J Am Coll Surg 215(4):453-466

30. Griffiths R, Beech F, Brown A et al (2014) Peri-operative care of the elderly 2014: Association of Great Britain and Ireland. Anaesthesia 69(Suppl 1):81-98

31. Dhesi, J. Peri-operative care for Older Patients Undergoing Surgery. British Geriatrics Society. Last amended Feb 4 2018. https ://www.bgs.org.uk/resources/peri-operative-care-for-older-patie nts-undergoing-surgery. Accessed 27 Feb 2019

32. Anaesthesia Perioperative Care Network Surgical Services Taskforce. The perioperative toolkit. Last amended Dec 13 2016. https://www.aci.health.nsw.gov.au/data/assets/pdf file/0010/342685/The_Perioperative_Toolkit.pdf. Accessed $2 \overline{7}$ Feb 2019

33. Alvarez-Nebreda ML, Bentov N, Urman RD et al (2018) Recommendations for preoperative management of frailty from the Society for Perioperative Assessment and Quality Improvement (SPAQI). J Clin Anesth 47:33-42

34. Wolters U, Wolf T, Stutzer H et al (1996) ASA classification and perioperative variables as predictors of postoperative outcome. BJA 77(2):217-222

35. Mak PH, Campbell RC, Irwin MG et al (2002) The ASA physical status classification: inter-observer consistency American Society of Anesthesiologists. Anaesth Intensive Care 30(5):633-640

36. Xue Q-L (2011) The Frailty Syndrome: definition and natural history. Clin Geriatr Med 27(1):1-15

37. Partridge JSL, Harari D, Dhesi JK (2012) Frailty in the older surgical patient: a review. Age Ageing 41(2):142-147

38. Cesari M (2019) Why and how do we measure frailty? Intern Emerg Med 14(1):5-6

39. Partridge JSL, Harari D, Martin FC et al (2014) The impact of pre-operative comprehensive geriatric assessment on postoperative outcomes in older patients undergoing scheduled surgery: a systematic review. Anaesthesia 69(Suppl 1):8-16

40. Eamer G, Taheri A, Chen SS et al (2018) Comprehensive geriatric assessment for older people admitted to a surgical service.
Cochrane Database Syst Rev. https://doi.org/10.1002/14651858. CD012485.pub2

41. Partridge JSL, Harari D, Martin FC et al (2013) The impact of pre-operative comprehensive geriatric assessment on postoperative outcomes in older patients undergoing scheduled surgery: a systematic review. Anaesthesia 69(Suppl. 1):8-16

42. Takahashi M, Takahashi M, Komine K et al (2017) The G8 screening tool enhances prognostic value to ECOG performance status in elderly cancer patients: a retrospective, single institutional study. PLoS ONE 12(6):e0179694. https://doi.org/10.1371/ journal.pone.0179694

43. Whittle AK, Kalsi T, Babic-Illman G et al (2017) A comprehensive geriatric assessment screening questionnaire (CGFiA-GOLD) for older people undergoing treatment for cancer. Eur J Cancer Care (Engl). https://doi.org/10.1111/ecc.12509

44. Prytherch DR, Whiteley MS, Higgins B et al (1998) POSSUM and Portsmouth POSSUM for predicting mortality. BJS 85(9):1217-1220

45. Ford MK, Beattie SB, Wljeysundera DN (2010) Systematic review: prediction of perioperative cardiac complications and mortality by the revised cardiac risk index. Ann Intern Med 152:26-35

46. Gragnano F, Cattano D, Calabro P (2018) Perioperative care of cardiac patient's candidate for non-cardiac surgery: a critical appraisal of emergent evidence and international guidelines. Intern Emerg Med 13(8):1185-1190

47. Partridge JSL, Sbai M, Dhesi J (2018) Proactive care of older people undergoing surgery. Aging Clin Exp Res 30(3):253-257

48. Jasper EV, Dhesi JK, Partridge JSL et al (2019) Scaling up perioperative medicine for older people undergoing surgery (POPS) services; use of a logic model approach. Clin Med (Lond) 19(6):478-484

Publisher's Note Springer Nature remains neutral with regard to jurisdictional claims in published maps and institutional affiliations. 